\title{
Correction to: New crystal structures of fluorinated a-aminophosphonic acid analogues of phenylglycine
}

\section{Weronika Wanat $^{1} \cdot$ Błażej Dziuk $^{1,2} \cdot$ Paweł Kafarski $^{1}$}

Published online: 27 February 2020

(C) Springer Science+Business Media, LLC, part of Springer Nature 2020

\section{Correction to: Structural Chemistry. https://doi.org/10.1007/s11224-019-01483-x}

Corrections are needed to the original version of this article. The in-text citations of figures in the section "NMR spectra characterization" are not in sequential order. Moreover, the sequence of figures. 3-8 does not coincide with that in the text. - Fig. 3. should show ${ }^{1} \mathrm{H}$ NMR spectrum, instead in the original paper ${ }^{1} \mathrm{H}$ NMR spectrum is presented in the Fig. 8.

- Fig. 4. should show ${ }^{13} \mathrm{C}$ NMR spectrum, instead in the original paper ${ }^{13} \mathrm{C}$ NMR spectrum is presented in the Fig. 3 .

- Fig. 5. should show $2 \mathrm{D} \mathrm{NMR}{ }^{13} \mathrm{C},{ }^{1} \mathrm{H}$ - HMQC spectrum, instead in the original paper $2 \mathrm{D} \mathrm{NMR}{ }^{13} \mathrm{C},{ }^{1} \mathrm{H}$ - HMQC spectrum is presented in the Fig. 6 .

- Fig. 6. should show ${ }^{19} \mathrm{~F}$ NMR spectrum, instead in the original paper ${ }^{19} \mathrm{~F}$ NMR spectrum is presented in the Fig. 4.

- Fig. 7. should show ${ }^{31} \mathrm{P}$ NMR spectrum, instead in the original paper ${ }^{31} \mathrm{P}$ NMR spectrum is presented in the Fig. 5.

- Fig. 8. should show $2 \mathrm{D} N \mathrm{NMR}^{31} \mathrm{P},{ }^{1} \mathrm{H}$ - HMQC spectrum of the compound 1 , instead in the original paper $2 \mathrm{D} \mathrm{NMR}{ }^{31} \mathrm{P}$, ${ }^{1} \mathrm{H}$ - HMQC spectrum is presented in the Fig. 7.

The corrected discussed section should read:

\section{NMR spectra characterization}

Due to low solubility in organic solvents, $\mathrm{D}_{2} \mathrm{O}$ with one drop of $\mathrm{NaOD}$ was used as solvent. ${ }^{1} \mathrm{H},{ }^{13} \mathrm{C},{ }^{19} \mathrm{~F}$ and ${ }^{31} \mathrm{P}$ NMR, 2D NMR ${ }^{13} \mathrm{C},{ }^{1} \mathrm{H}-\mathrm{HMQC}$ and $2 \mathrm{D}$ NMR ${ }^{31} \mathrm{P},{ }^{1} \mathrm{H}-\mathrm{HMQC}$ spectra

The online version of the original article can be found at https://doi.org/ 10.1007/s11224-019-01483-x

Weronika Wanat

weronika.wanat@pwr.edu.pl

1 Faculty of Chemistry, Wroclaw University of Science and Technology, Wybrzeze Wyspianskiego 27, 50-370 Wroclaw, Poland

2 Faculty of Chemistry, University of Opole, Opole, ul. Oleska 48, 45-052 Opole, Poland of the representative compounds (1) are showed. Doublet signal on the ${ }^{1} \mathrm{H}$ NMR spectrum at $3.75 \mathrm{ppm}$ with ${ }^{2} J_{(H-P)}=15-16 \mathrm{~Hz}$, is a characteristic feature of these compounds and has been assigned to the methene hydrogen of the CHP fragment. The exchangeable $\mathrm{N}-\mathrm{H}$ and $\mathrm{OH}$ proton signals appears as broad singlet at $4.68 \mathrm{ppm}$. The aromatic protons $\mathrm{CH}_{\mathrm{ar}}$ from phenyl ring resonates in the expected region from 6 to 8 ppm (Fig. 3). As a consequence of proton-proton and proton-fluorine (in compounds $\mathbf{2 , 3}$ and $\mathbf{4}$ with substitution of hydrogen atoms by fluorine atoms in aromatic moiety) the multiplicities of these signals are observed. On the ${ }^{13} \mathrm{C}\left\{{ }^{1} \mathrm{H}\right\}$ spectrum (Fig. 4) characteristic doublet at around $\delta=55 \mathrm{ppm}$ with large value of coupling con$\operatorname{stant}\left({ }^{1} J_{(C-P)}=128.5 \mathrm{~Hz}\right)$ is generated as a result of interaction of the carbon atom directly related to the phosphorus (CHP). The two-dimensional spectrum ${ }^{13} \mathrm{C},{ }_{1}^{1} \mathrm{H}-\mathrm{HMQC}$ (Fig. 5) confirm correlations of that signal with doublet in proton spectra ${ }^{2} J_{(H-}$ $\left.{ }_{P}\right)$. The quaternary carbon atom of trifluoromethyl moiety is visible at $124.54 \mathrm{ppm}$ as doublet of quartets with two coupling constant: first high ${ }^{1} J_{(\mathrm{C}-\mathrm{F})}=271 \mathrm{~Hz}$ and second very low about $1 \mathrm{~Hz}$ coupling as probable result from additional correlation with phosphorus atom (Fig. 4-B). In a similar manner resonate carbon atom directly bounded to $\mathrm{CF}_{3}$ moiety, which was detected also as doublet of quartets at $127.43 \mathrm{ppm}$ and the coupling constants occurs in the range: ${ }^{1} J_{(\mathrm{C}-\mathrm{F})}=32.0 \mathrm{~Hz}$ and ${ }^{2} J_{(\mathrm{C}-\mathrm{F})}=2.9 \mathrm{~Hz}$ (Fig. 4-A). The remaining signals have been assigned to phenyl ring carbon atoms and their multiplicity is associated with the presence of fluoro substituents in aromatic rings. ${ }^{19} \mathrm{~F}\left\{{ }^{1} \mathrm{H}\right\}$ NMR spectra affirm presence of fluorine atoms in the structure and resonated in the expected region as multiplets for compounds 2, 3 and $\mathbf{4}$ and as singlet for $\mathrm{CF}_{3}$ moiety for compound $\mathbf{1}$ (Fig. 6). Fluorine atoms substitution in the aromatic ring contribute to multiplicities of phosphorus signals on the ${ }^{31} \mathrm{P}\left\{{ }^{1} \mathrm{H}\right\}$ NMR spectra and long-range couplings between P-F atoms are very good visible by 4, 5, 6 or even 7 bonds. In the case of compound 1 quartet with low coupling constant of ${ }^{7} J_{(\mathrm{P}-\mathrm{F})}=2 \mathrm{~Hz}$ is observed (Fig. 7). The $2 \mathrm{D}$ NMR ${ }^{31} \mathrm{P},{ }^{1} \mathrm{H}-\mathrm{HMQC}$ spectrum verified interaction of the methene hydrogen $\left({ }^{2} J_{(H-P)}\right)$ with phosphorus atom in CHP skeleton (Fig. 8).

The corrected sequence of the figs. 3-8 should be: 


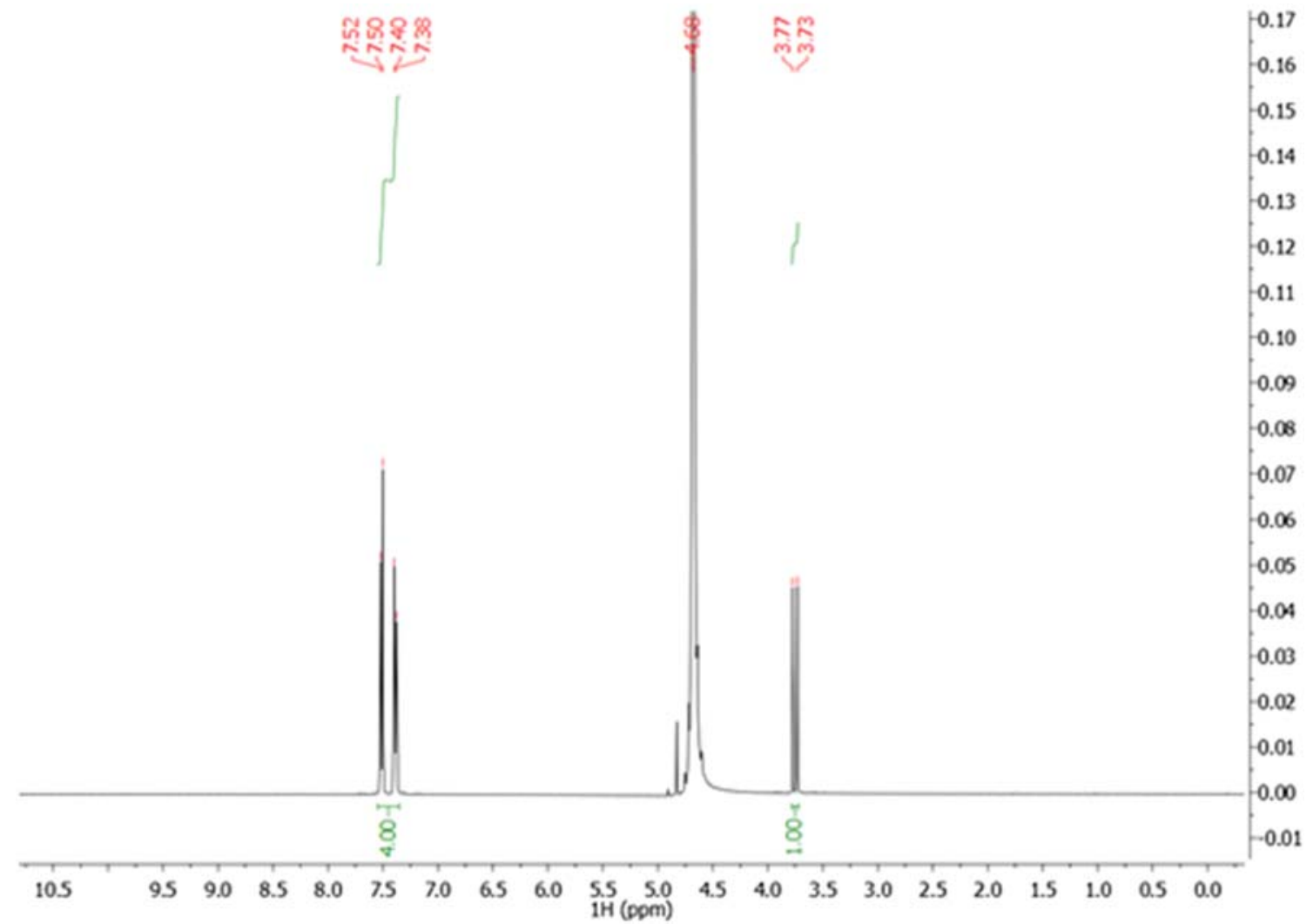

Fig. $3{ }^{1} \mathrm{H}$ NMR spectrum of the compound 1

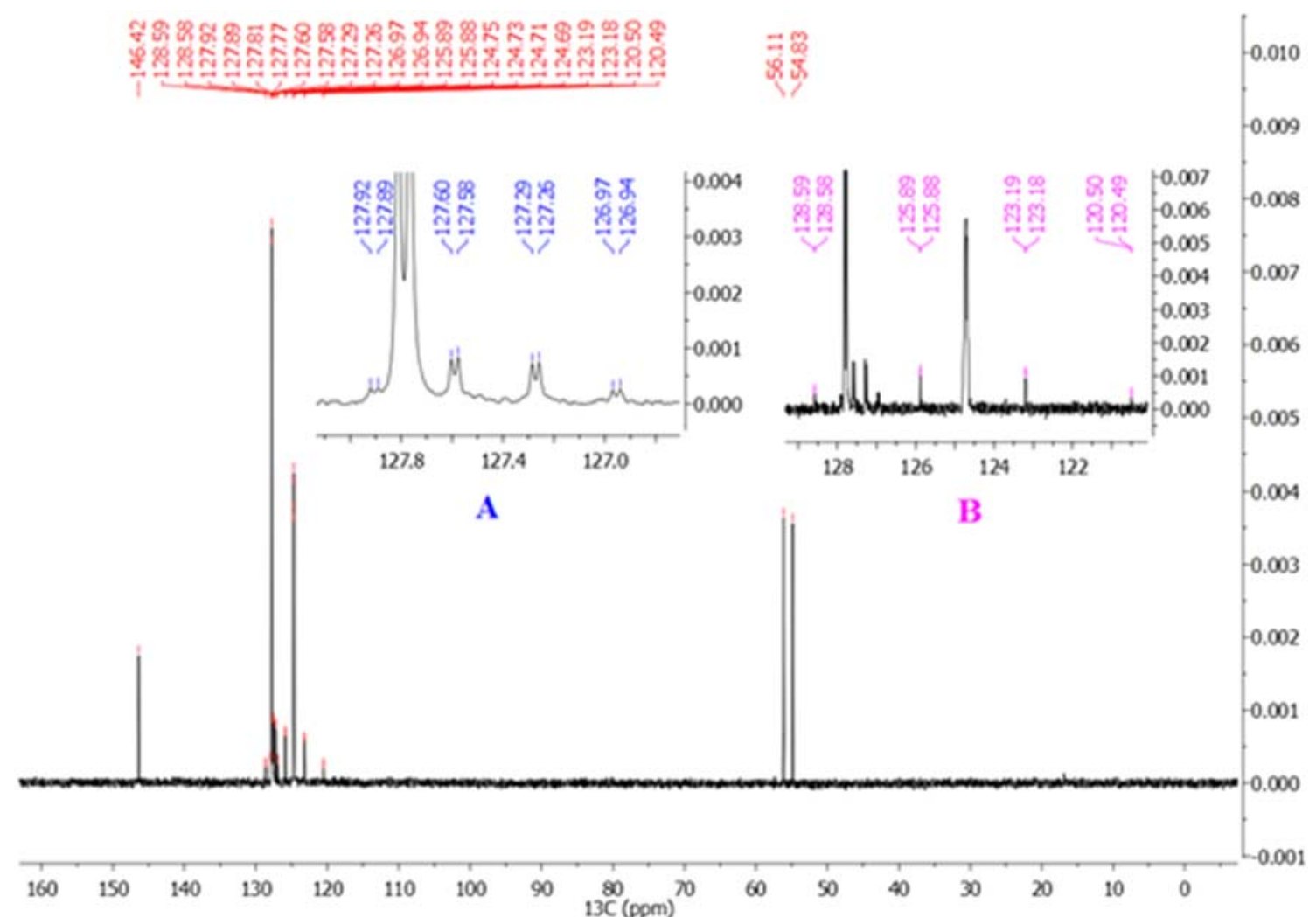

Fig. $4{ }^{13} \mathrm{C}\left\{{ }^{1} \mathrm{H}\right\}$ NMR spectrum of the compound 1. Extension of quartet signals $\mathbf{C}_{\mathrm{ar}}-\mathrm{CF}_{3}(\mathbf{A})$ and $\mathbf{C F}_{3}-\mathrm{C}_{\mathrm{ar}}(\mathbf{B})$ have been showed as blue peaks and pink peaks, respectively 
Fig. 5 2D NMR ${ }^{13} \mathrm{C},{ }^{1} \mathrm{H}-\mathrm{HMQC}$ spectrum of the compound 1

Fig. $6{ }^{19} \mathrm{~F}\left\{{ }^{1} \mathrm{H}\right\}$ NMR spectrum of the compound 1
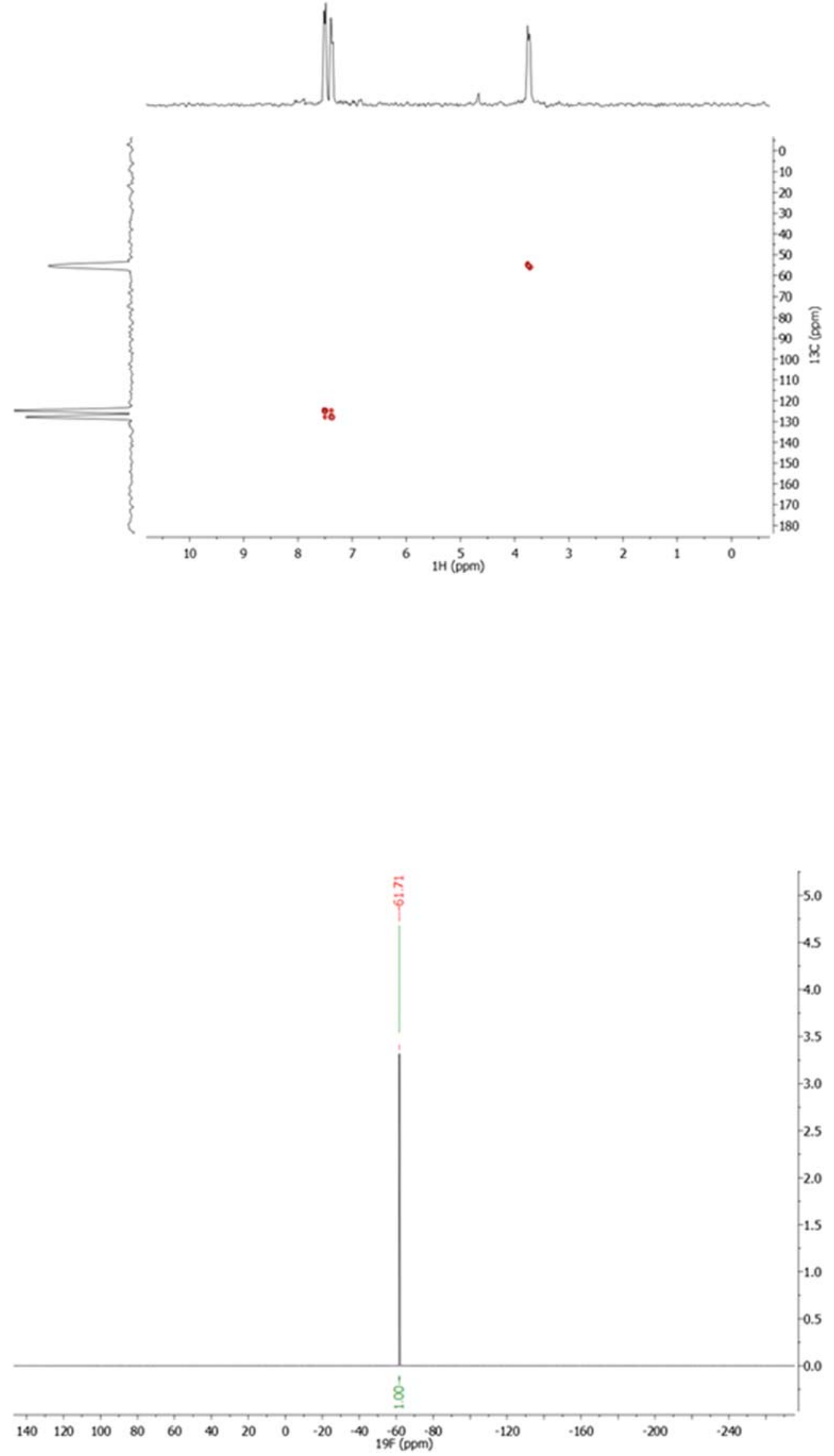
Fig. $7{ }^{31} \mathrm{P}\left\{{ }^{1} \mathrm{H}\right\}$ NMR spectrum of the compound $\mathbf{1}$. The longrange couplings between phosphorus and fluorine generate quartet signal

Fig. 8 2D NMR ${ }^{31} \mathrm{P},{ }^{1} \mathrm{H}-\mathrm{HMQC}$ spectrum of the compound 1

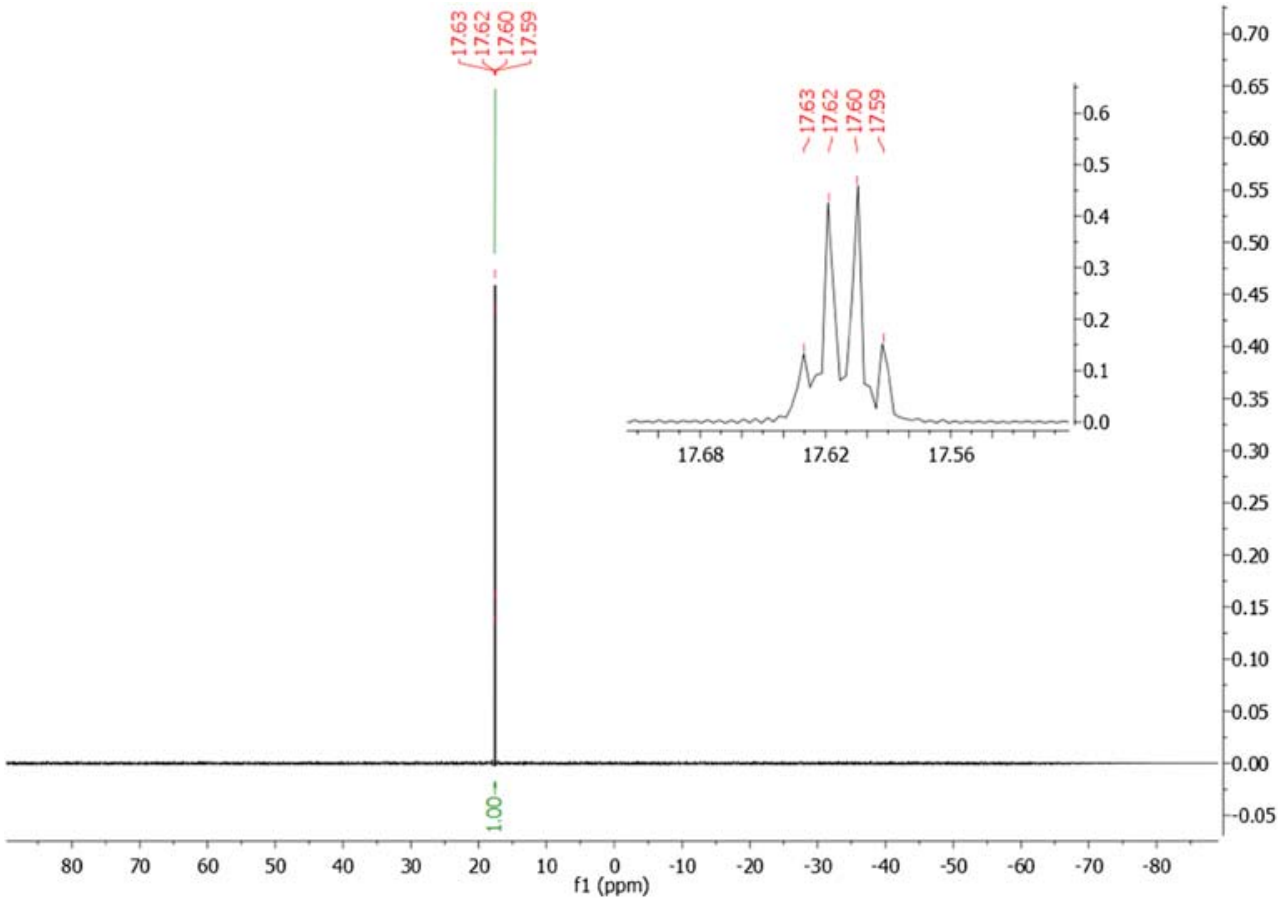

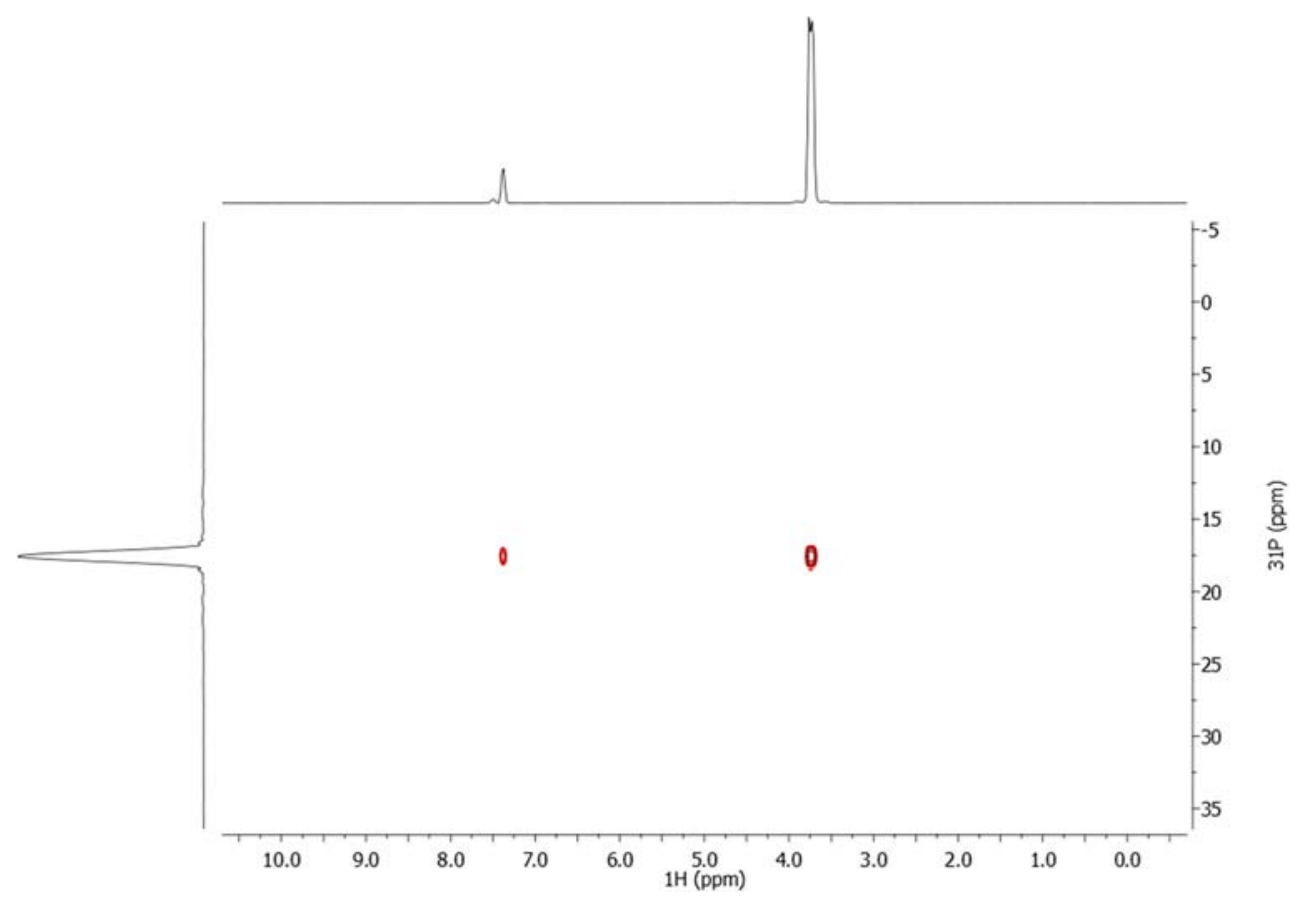


The authors apologize for the oversight and further state that the changes made to the in-texts citations and sequence of figures don't have an impact to the overall outcome of the study. 